\title{
O mototurismo e o desejo de viajar no estilo de vida Harley Davidson: um estudo de caso sobre o Chapter HOG - The One Curitiba (Paraná, Brasil)
}

\section{The 'mototourism' and the wanderlust Harley Davidson lifestyle: a study about the Chapter HOG - The One Curitiba (Paraná, Brazil)}

\author{
Izabela Bernardis Pacheco (PACHECO, I. B.) ${ }^{*}$ \\ Paula Grechinski Demczuk (DEMCZUK, P. G.) ${ }^{* *}$.
}

RESUMO - Neste artigo se teve como principal objetivo analisar a relação do grupo HOG (Harley Owners Group) com a atividade turística. Dessa forma, estabeleceu-se como objetivos específicos: levantar informações sobre o grupo de motociclistas do Chapter HOG - The One Curitiba (PR); identificar os principais destinos de viagens deste grupo de motociclistas; analisar como se organizavam para as viagens; e identificar os eventos organizados pelo Chapter HOG - The One Curitiba (Paraná, Brasil). Como metodologia para alcançar os objetivos propostos, foi realizada pesquisa teórica; análise de conteúdo em redes sociais; entrevista com membros da diretoria do grupo; e aplicação de questionários com motociclistas. Foi possível concluir que os motociclistas do Chapter HOG - The One Curitiba estavam se relacionando com a atividade turística com frequência, principalmente por fazer uso da infraestrutura turística, movimentando assim o trade turístico. Contudo, a relação do grupo ia, além disso, pois se percebeu que os membros realizavam viagens pelo simples prazer que elas proporcionam, onde o que realmente importava não era o destino em si, mas as emoções que o deslocamento nas motocicletas proporcionava.

Palavras-chave: Chapter HOG - The One Curitiba (PR); Harley Davidson; Mototurismo; Eventos; Viagens.

ABSTRACT - This article aims to analyze the relationship of the group HOG (Harley Owners Group) with tourist activity. It intend to accomplish the following specific objectives: gather information about the group Chapter HOG - The One Curitiba (Paraná, Brazil); identify the major travel destination of this motorcyclists group; analyze how they organized the trips; and identify the events organized by Chapter HOG - The One Curitiba. The methodology to achieve the proposed objectives was conducted with theoretical research, content analysis in social networks, interviews with board members of the group, and questionnaires with bikers. At the end of the research, it was possible to conclude that the Chapter HOG bikers often practice a touristic activity; they use many kinds of touristic infrastructure, and move the touristic trade. However, the relationship of the group goes beyond that, because the members make

\footnotetext{
* Formação: Graduação em Turismo (Bacharelado) pela Universidade Estadual do Centro Oeste do Paraná (UNICENTRO). Endereço físico para correspondência: Avenida dos Jambos, 1225 (Centro). CEP: 78320-000 - Juína/MT (Brasil). E-mail: zabynha@ hotmail.com

** Formação: Graduação em Turismo (Bacharelado) pela Universidade Estadual do Centro Oeste do Paraná (UNICENTRO). Mestrado em Gestão do Território pela Universidade Estadual de Ponta Grossa (UEPG). Atividade profissional: Professora Assistente A, lotada no Departamento de Turismo da Universidade Estadual do Centro Oeste (UNICENTRO). Endereço físico para correspondência: Rua André Filipak, 160, casa 04 (Bairro Alto da Glória). CEP: 84500-000 - Irati - PR - Brasil. E-mail: peul_t@hotmail.com
} 
trips only for the pleasure they provide, and it is not the destination that matters, but the emotions that the shift in motorcycles provides.

Key words: Chapter HOG - The One Curitiba (PR); Harley Davidson; Mototourism; Events; Travels. 


\section{INTRODUÇÃO}

Este artigo tem como tema a relação de grupos de motociclistas com a atividade turística. Para esta análise, foi estabelecido como objeto de estudo o Chapter HOG (Harley Owners Grup) - The One Curitiba (PR). O Harley Owners Grup é uma organização com mais de um milhão de motociclistas ${ }^{1}$ do mundo inteiro unidos pela paixão à Harley Davidson, sendo que o Chapter HOG - The One Curitiba (PR) possui mil e setenta e oito pessoas ${ }^{2}$ ligadas a ele.

Segundo Scharf (2011) a empresa Harley Davidson busca desenvolver métodos a fim de fidelizar e proporcionar exclusividade a seus consumidores, através do marketing experiencial, como é o caso do grupo HOG, criado em 1983 nos Estados Unidos da América, por proprietários de Harley Davidson com o objetivo de compartilhar a paixão por suas motocicletas, e também a criação das Ladies Of Harley (LOH) um grupo exclusivo de mulheres proprietárias de Harley Davidson. O mesmo autor observa ainda o desenvolvimento da revista HOG, com publicação trimestral, e também a criação de um selo de qualidade para as agências de viagens focadas nesses consumidores.

Assim, neste artigo se teve como objetivo geral estudar a relação do Chapter HOG - The One Curitiba (PR), com a atividade turística. Para o alcance deste objetivo foi necessário: levantar informações sobre o grupo de motociclistas do Chapter HOG The One Curitiba (PR); identificar os principais destinos de viagens desse grupo de motociclistas; analisar como se organizavam para as viagens; e identificar os eventos organizados pelo Chapter HOG - The One Curitiba (PR).

Com o objetivo de levantar informações sobre os membros do Chapter HOG The One Curitiba (PR), além de pesquisa teórica em páginas eletrônicas e artigos científicos relacionados ao tema, utilizou-se da técnica de análise de conteúdo na rede

\footnotetext{
${ }^{1}$ Informação obtida na página eletrônica oficial da Harley Davidson. Disponível em: <http://www.harleydavidson.com/pt_BR/Content/Pages/HOG/HOG.html?locale=pt_BR\&bmLocale=pt_BR>. Acesso em: 07/08/13.

${ }^{2}$ Informação obtida em análise de conteúdo na rede social do grupo, HOG CURITIBA CHAPTER THE ONE OFICIAL. Disponível em: <https://www.facebook.com/groups/238399322934133/?fref=ts>. Acesso desde março de 2013.
} 
social $^{3}$ do grupo que é objeto de estudo deste trabalho. No caso desta pesquisa, foram analisados fotos, comentários e ideias publicadas por membros a respeito das viagens e eventos realizados.

Ainda com o mesmo objetivo, utilizou-se a técnica de entrevista com três membros da diretoria do Chapter HOG - The One Curitiba. As entrevistas seguiram um roteiro de questões previamente elaborado e apresentado aos entrevistados com antecedência, os resultados obtidos possibilitaram maior aprofundamento sobre a história do grupo, seus principais objetivos e para levantamento dos eventos organizados pelo Chapter HOG - The One Curitiba (PR). Foram entrevistados apenas três integrantes da diretoria, pois as respostas obtidas com eles foram consideradas suficientes para obter as informações necessárias ao alcance dos objetivos propostos.

A fim de identificar os principais destinos de viagens desse grupo de motociclistas e definir o perfil dos membros do Chapter HOG - The One Curitiba (PR) foram distribuídos duzentos questionários com dezenove perguntas abertas e fechadas. Desses duzentos questionários, apenas trinta e nove foram respondidos e o resultado da pesquisa se encontra no tópico referente à apresentação dos resultados.

Esta pesquisa foi desenvolvida entre os meses de março à outubro de 2013, com a colaboração dos integrantes do Chapter HOG - The One, e também da Concessionária The One Harley Davidson, contudo este é apenas um dos muitos grupos de motociclistas espalhados pelo mundo, que possuem como principal essência o espirito de aventura. Dessa forma, com este trabalho se pretendeu contribuir para a difusão do estudo e da prática do mototurismo.

\section{O TURISMO E O MOTOTURISTA}

A partir do momento em que o turismo passa a ser estudado por diversas áreas do conhecimento, sua complexidade e diversidade são reconhecidas. Desta forma o estudo das motivações torna-se amplo e diversificado. Criaram-se com isso algumas definições, focando as necessidades e características específicas dos turistas. (COOPER et al, 2001). No que tange à necessidade de viajar do indivíduo, Burns (2002) menciona

\footnotetext{
${ }^{3}$ HOG CURITIBA CHAPTER THE ONE OFICIAL. Disponível em: <https://www.facebook.com/groups/238399322934133/?fref=ts>. Acesso desde março de 2013.
} 
que o turismo envolve ideias e características particulares de pessoas que influenciam outras pessoas sobre os locais a serem visitados. Já no que diz respeito às necessidades de viagens a lazer Siqueira (2004, [s./p.]) relata que:

\begin{abstract}
Enquanto uns acreditam que a necessidade de viajar é algo criado pela classe dominante, outros crêem que o contato com a natureza, a ânsia por liberdade e independência têm também nas viagens as projeções dos anseios internos dos seres humanos. Neste aspecto, considerando-se anseios internos como algo não-inerente à sociedade e aos padrões ideológicos, seria a viagem algo necessário aos indivíduos independente dos estímulos criados pela mídia, por exemplo.
\end{abstract}

Para esses dois autores, a pessoa tem a necessidade de realizar viagens, independente de suas preferências, e as viagens são meios de autoconhecimento, bem como o conhecimento de outras culturas e pessoas. Explorando mais profundamente esta ideia, a necessidade de viajar vem de uma busca por superação pessoal, sendo que “o importante não é o percurso, mas as experiências vivenciadas no percurso." (IESEN; BECKER, 2003, p. 95) Dessa forma, as motivações partem das expectativas individuais ou de um grupo específico.

Avaliando o turismo a partir de agrupamentos com interesses específicos, é possível visualizar com maior precisão as principais características específicas de cada segmento, através das estatísticas disponibilizadas exclusivamente para o grupo a ser estudado. Com esse método também se torna mais eficaz a produção e distribuição de produtos turísticos, uma vez que se identifica mais facilmente o público-alvo e suas principais características (BENI, 2003).

Dessa forma observa-se que as viagens realizadas por motociclistas enquadramse a uma denominação própria conhecida popularmente como mototurismo, que é o tipo de turismo realizado individualmente ou em grupos por pessoas que têm como motivação principal o seu meio de transporte, a motocicleta. No entanto não identificouse haver estudos científicos que possam precisar esta definição, isso pode ser explicado pela especificidade dessa atividade, como também a recente aceitação dessas viagens como uma prática turística. O objeto de estudo deste trabalho, Chapter HOG (Harley Owners Grup) - The One Curitiba, Paraná, consiste em um grupo de motociclistas que têm características bem definidas e afinidades em comum. 
Assim como na segmentação do turismo, separar os grupos de turistas em grupos homogêneos com interesses semelhantes proporciona maior conhecimento do público que se pretende atingir, define a produção de produtos turísticos específicos para esse segmento e a distribuição desse produto faz-se de forma mais eficaz.

Nesse sentido apresenta-se a seguir, sobre a criação de motoclubes e a consequente prática do mototurismo, será apresentado também um panorama geral da criação da motocicleta e as vantagens que esse meio de transporte gerou na prática do turismo no século 19. A partir dessas explanações será possível conhecer em síntese o objeto de estudo deste trabalho.

\section{O MOTOTURISMO E O MOTOCLUBISMO}

Segundo Provetti (2013b) depois da invenção da bicicleta, muitos visionários dedicaram-se a projetar um motor a fim de impulsioná-la. Na mesma obra consta que o responsável pela criação da primeira motocicleta com motor a gasolina foi o alemão Gottlieb Daimler, em 1885, que instalou um motor em uma bicicleta de madeira. Em 1894 surgiu a primeira fábrica de motocicletas, na Alemanha chamada Hildebrandt \& Wolfmüller (PROVETTI, 2013b).

O mesmo autor, em outra publicação (PROVETTI, 2013a) destaca que depois de alguns aprimoramentos, as motocicletas tornaram-se um bem desejável pelos aventureiros que desafiavam a nova máquina, esses mesmos aventureiros começaram então a organizar corridas e rallys. A partir desses eventos desportivos inicia-se a criação de motoclubes para unir os indivíduos que possuíam como principal afinidade, o interesse por esse meio de transporte peculiar (PROVETTI, 2013a).

De acordo com Provetti (2013d) com a criação de motoclubes, os eventos passam a ter caráter não apenas competitivo, mas também social a fim de unir os indivíduos que possuíam essa preferência em comum. "Lentamente formalizaram os escudos, as cores, que passaram a defender com sua honra, adaptando a hierarquia militar em uma estrutura de irmandade, [...] sob os cargos eletivos das associações", em pouco tempo os fins de semana ficaram pequenos para tantas 'emoções', e não raro alguns motociclistas não voltavam para suas casas (PROVETTI, 2013d, [s./p.]). 
No mesmo texto o autor menciona que a união de tantos homens, principalmente ex-soldados, reunidos durante dias seguidos, somada à idolatria exagerada por parte de alguns, tanto pela pátria quanto por seus clubes de motociclistas, além da ingestão de bebidas alcoólicas, e o apelo selvagem dos filmes Hollywoodianos mancharam a imagem do motociclista de uma forma quase que insolúvel. Provetti (2013d) menciona ainda que foi apenas no final da década de 60 e início dos anos 70 que ocorreu uma reformulação da figura do motociclista, assumindo assim uma postura de liberdade e resistência ao sistema, chamada de contracultura ${ }^{4}$.

Segundo Iesen e Becker (2003) o primeiro encontro de motociclistas com caráter não mais exclusivamente desportivo, aconteceu na década de 60, nos Estados Unidos, a fim de resgatar o símbolo de liberdade da Route 66, estrada mais famosa que ligava Chicago a Los Angeles.

Nesta década, o estilo "motociclístico" assumiu uma nova imagem e vitalidade dentro do aspecto de ampliação de estilos de vida contemporâneo. Estes movimentos revitalizaram a reputação dos motociclistas e foram responsáveis por atrair motociclistas cujo único desejo era projetar a imagem de diversão saudável, contribuição a comunidade e a liberdade inerentes a experiência das Harleys Davidson (PROVETTI, 2013d, [s./p.]).

Deste momento em diante, participar de um grupo de motociclistas passa a ser também motivo de status e orgulho, e as grandes montadoras criam seus próprios grupos de motociclistas que unidos às associações de classe, promovem e produzem grandes eventos (PROVETTI, 2013d).

Dessa forma a motocicleta deixa de ser utilizada apenas como meio de transporte individual, e passa a ser também um instrumento para a união de indivíduos que têm como preferência as viagens em grupo (PALHARES, 2002).

\begin{abstract}
Os motoclubes ainda são a melhor forma de expressar o motociclismo estradeiro, mas é bom lembrar que todas as corridas que hoje vemos mundo afora começaram com eventos promovidos pela AMA-USA. Tais eventos foram os precursores de tudo o que vem a ser o mercado de motos hoje. Os motoclubes podem até perder o seu pique de crescimento, mas nunca vão perder o glamour. (MOTO ONLINE, 2013).
\end{abstract}

\footnotetext{
${ }^{4}$ CONTRACULTURA: O termo "contracultura" foi inventado pela imprensa norte-americana, nos anos 60, para designar um conjunto de manifestações culturais novas que floresceram, não só nos Estados Unidos, como em vários outros países, especialmente na Europa, e embora com menor repercussão, na América Latina. Na verdade, é um termo adequado porque uma das características básicas do fenômeno é o fator de se opor, de diferentes maneiras, à cultura vigente e oficializada pelas principais instituições das sociedades do Ocidente. (PEREIRA, 1983, p. 8).
} 
Dentre os eventos motociclísticos, um dos maiores e mais tradicional deles é o Daytona Bike Week, realizado na Flórida, Estados Unidos da América, o evento possui mais de setenta anos de tradição unindo apaixonados pelo motociclismo, independente da marca da motocicleta, possuindo inclusive pacotes de viagem exclusivos, desenvolvidos e comercializados por agências especializadas (HARLEY DAVIDSON, 2013).

A crescente difusão desse segmento faz crescer esse mercado. "A partir de último terço do século XX o equipamento motociclístico começa a desenvolver-se tecnologicamente, com novos materiais a aparecer no mercado, mais confortáveis e mais seguros" (TURISMO DE MOTO, 2013 [s./p.]). O mesmo texto observa que através desse desenvolvimento tecnológico dos equipamentos de conforto e segurança, aumentou consideravelmente não apenas os clubes de motociclistas e os grandes eventos motociclísticos, mas também os equipamentos e serviços turísticos que evidenciam esse público, como restaurantes temáticos, hotéis em beira de estrada e agências especializadas, surgindo a partir de então o mototurismo.

Como o próprio nome indica, o Mototurismo é um conceito de viagem cujo meio de transporte é a moto, e caracteriza-se essencialmente pelo espírito de aventura, liberdade e descoberta [...] O fenômeno sócio-econômico e cultural do mototurismo (como o conhecemos hoje) ocorre a partir do final da década de 60 e início dos anos 70. (PROVETTI, 2013b [s./p.]).

O mototurismo é um segmento relativamente novo no que diz respeito a estudos científicos e a elaboração de conceitos. Contudo, deve-se considerar que esta é uma atividade turística que faz uso de equipamentos e serviços turísticos, gerando relações sociais e econômicas entre os grupos de motociclistas e os locais visitados por eles. Dessa forma, observa-se a existência de empreendimentos, como as agências de viagens, que descobriram nesse segmento uma oportunidade de mercado.

Segundo (PETROCCHI, 2004), as diferenças proporcionam uma vantagem competitiva. É a partir disso que surgem empresas especializadas em determinado segmento de mercado, como é o caso das agências de mototurismo.

Ao contrário dos demais meios de transporte rodoviários, as motocicletas são comercializadas pelos agentes de viagens, geralmente para grupos específicos e bastante segmentados de clientes, como é o caso das agremiações e clubes dos aficionados pelo motociclismo, que, muitas vezes, organizam itinerários 
turísticos com motocicletas. Principalmente em destinos internacionais, os clientes não levam seu próprio veículo, necessitando locar uma motocicleta para realizar a viagem (BRAGA, 2008, p. 154).

A autora destaca ainda, que esse segmento de mercado é mais explorado nos Estados Unidos, onde as agências especializadas fornecem serviços de locação, guias, traslado e apoio ao viajante com esclarecimentos detalhados quanto as características das vias de rodagem, as condições gerais da contratação do serviço e as especificações da motocicleta a ser locada. E ainda enfatiza que de modo geral "o cliente que opta por esse meio de transporte o faz mais pela paixão pelo motociclismo do que pelo itinerário da viagem" (BRAGA 2008, p. 154). Afirmando assim que para o mototurista o desejo de vivenciar a experiência durante a viagem é mais importante que o destino final.

\section{O ESTILO DE VIDA HARLEY DAVIDSON}

A história da Harley Davidson teve início em 1903, em Milwaukee (EUA), com dois jovens amigos: William S. Harley e Arthur Davidson, que conseguiram vencer os obstáculos impostos pela mecânica, e criaram a primeira motocicleta Harley Davidson em um barracão nos fundos do quintal da família Davidson, e ali produziram suas próprias motocicletas, e é então que surge uma das marcas de maior reconhecimento do motociclismo: a Harley Davidson (PROVETTI, 2013d).

Especializada em fabricar principalmente motocicletas de grande porte, modelos Custom e Touring, definidos pela Associação Brasileira dos Fabricantes de Motocicletas (ABRACICLO, 2012) como motocicletas 'estradeiras', ambas priorizam mais o conforto do que a velocidade e são destinadas para longas viagens.

Segundo Azevedo e Araújo (2010) a marca Harley Davidson e seus fundadores passaram por momentos respeitáveis da história mundial. Os autores afirmam que um deles foi o pedido feito pelo governo americano para que a empresa desenvolvesse motocicletas durante a Primeira Guerra Mundial, quando foram produzidas e fornecidas 20 mil motocicletas para o exército americano, já para a Segunda Guerra o número de motocicletas fornecidas foi de noventa mil motocicletas e sidecars.

Segundo Azevedo e Araújo (2010, p. 3): 
Essa presença em momentos marcados pelo ideal nacionalista norteamericano tornou a Harley Davidson um símbolo nacional. Veteranos de guerra tornam-se seus principais compradores. Também desse vínculo, parece advir a associação da Harley com poder, força, masculinidade, a algo que é maior que o homem em si e ao mesmo tempo é uma extensão dele.

Em 1969 um fato pitoresco aconteceu com a Harley, ela foi vendida para a American Machine \& Fondry Company (AMF), que injetou US\$ 60 milhões na Companhia para aumentar a produção, porém, a qualidade das motocicletas decaiu, prejudicando a imagem de imponência e força da empresa, unido a isso a ascendência das motocicletas japonesas no mercado norte-americano e o aumento no preço da gasolina, fez com que a AMF oferecesse a Harley Davidson Motor Company a seus antigos donos. (MUNDO DAS MARCAS, 2006). Segundo a mesma fonte, somente em junho de 1981, William G. Davidson, mais outros 12 executivos retomaram posse da Harley Davidson.

A recessão financeira e queda na qualidade das motocicletas produzidas pela AMF fizeram com que fosse necessário inovar, e a empresa começou então a vender roupas e acessórios sob a grife Harley Davidson - o que ainda não era suficiente, pois os dirigentes queriam conquistar novos clientes. (MUNDO DAS MARCAS, 2006). No aniversário de 80 anos da marca, foi fundado o Harley Owners Group (HOG), e essa foi sem dúvida a jogada de marketing mais eficaz utilizada pela empresa (MUNDO DAS MARCAS, 2006).

O HOG (Harley Owners Group) é um grupo internacional exclusivo de proprietários de motocicletas Harley Davidson, fundado em 1983 na cidade matriz da marca, Milwaukee (EUA), com o objetivo de difundir a marca e atrair novos consumidores. (IESA HARLEY DAVIDSON, 2013). A mesma fonte afirma que a vantagem em ter uma empresa que organizasse e patrocinasse os eventos e rallys dos motociclistas, tornou-se uma grande atração para os apaixonados pelas motos 'estradeiras'. Segundo Azevedo e Araújo (2010, p. 7), a partir da fundação do grupo HOG, "O consumidor agora se une à família Harley".

A criação de um grupo de motociclistas apaixonados por uma marca era algo novo e diferente, "era uma grande e atrativa novidade ter uma empresa que patrocinava e organizava rallys e eventos, os quais mantinham os donos das motos em contato com a Harley Davidson e entre eles mesmos." (IESA HARLEY DAVIDSON, 2013 [s./p.]). 
De acordo com a publicação citada no parágrafo acima, a partir dos anos 1990 o estilo de vida do HOG se alastrou pelo mundo inteiro, deixando de ser um símbolo de rebeldia e passou a ser considerado um status. "Agora a imagem era de status, pois o proprietário de uma Harley tinha a oportunidade de se tornar membro de um grupo de elite, que tinha como objetivo apenas se divertir e demonstrar a paixão pelas motos" (IESA HARLEY DAVIDSON, 2013 [s./p.]). E no dia 13 de julho de 1998, cinquenta mil harleyros partiram para Milwaukee, para comemorar o $95^{\circ}$ aniversário do feito dos jovens William S. Harley e Arthur Davidson. (BORGES; GODINHO, 2008). No ano de 1999 o número de Chapters chegou a mil cento e cinquenta e sete, tendo quinhentos mil membros associados. (IESA HARLEY DAVIDSON, 2013).

Segundo folheto informativo disponibilizado pela diretoria do Chapter - HOG The One Curitiba (PR), ao comprar uma Harley Davidson na concessionária, a pessoa recebe uma carteirinha de associado, válida por um ano. Essa carteirinha proporciona ao membro HOG diversas vantagens em qualquer parte do mundo, descontos de $10 \%$ na compra de peças, acessórios, e motocicletas, o mesmo desconto se aplica aos serviços de manutenção. No mesmo material consta que o associado também recebe: condições especiais na participação dos eventos promovidos pela Harley Davidson; cursos de pilotagem; participação nos cafés da manhã dos sábados nas concessionárias; facilidades nas viagens realizadas pelo grupo e calendário exclusivo dos passeios e eventos agendados. (IESA HARLEY DAVIDSON, 2013).

No mesmo folheto se explana que a diretoria do Chapter HOG, é eleita anualmente de forma voluntária, tendo em vista os seguintes objetivos: rodar sempre juntos seja em pequenos passeios ou ações sociais e beneficentes, cultivando as amizades antigas e fazendo novas.

De acordo com Provetti (2013c) cada Chapter é patrocinada pela concessionária Harley Davidson que é ligada ao HOG nacional. O mesmo autor afirma que os associados ativos do HOG consomem $30 \%$ a mais em roupas, acessórios e eventos que outros proprietários. Vale mencionar ainda que dentro do HOG, há um grupo exclusivo para mulheres proprietárias de Harleys Davidson, denominado Ladies Of Harley (LOH), que além de realizarem suas próprias reuniões, ajudam a organizar os eventos da marca. (PROVETTI, 2013c). 
Desde 1983 quando o HOG foi fundado, o grupo também sofreu alterações e renovações de seus associados, dessa forma através do relacionamento continuo entre ambos é possível visualizar essas mudanças sem muitos esforços, renovando a abordagem ao público ou cliente, quando necessário, conforme ressalta Scharf (2011, p. 109):

\begin{abstract}
A própria fabricante, antes apoiadora do 'macho', com botas sujas, barba, roupas de couro e atitudes agressivas em bares de estrada, migra seu apoio para outro tipo de homem másculo: o lutador de MMA (Mixed Martial Arts), com equipe de acompanhamento nos treinos, altas bolsas de aposta e reconhecimento do público, como se fossem gladiadores dos tempos modernos. As lutas de MMA têm apresentado peças publicitárias no chão e nas laterais do octógono, em um esforço de patrocínio bastante intenso da marca.
\end{abstract}

O envolvimento direto das famílias Harley e Davidson nos projetos e na produção das motocicletas, a participação dos irmãos Davidson nos rallys de motocicleta, a venda e recompra da companhia, e a criação do HOG são fatores que contribuíram para criar uma imagem de tradição da Companhia Harley Davidson, de acordo com Scharf (2011). Segundo o mesmo autor, os consumidores procuram memórias afetivas, sensações e simbolismos que possibilitem uma experiência holística e duradoura. Assim a tradição familiar e a imagem de patriotismo e poder criado no pósguerra, podem ser considerados fatores influenciadores no momento da decisão da compra, e consequentemente a fidelidade dos clientes. (SCHARF, 2011).

\footnotetext{
A Harley Davidson fornece mais do que motocicletas. Proporcionam todo um conjunto de sensações. Oferece participação numa comunidade. Promove excursões aventurosas. Acena com um estilo de vida. O produto total vai muito além de um simples veiculo motorizado com duas rodas. (SCHARF 2011, p. 103).
}

Todas as estratégias de marketing mencionadas unidas à mística da marca são fatores que contribuem para fazer da Harley Davidson, a maior montadora de motocicletas do mundo, além de ter revitalizado a imagem da marca e estreitado os laços entre da empresa e seus clientes, também elevaram a marca a ícone do mundo motociclístico. (REVISTA QUATRO RODAS 2013). Segundo a consultoria da 
Interbrand $^{5}$, a Harley Davidson é a $100^{\text {a }}$ marca mundial em valor e a primeira entre as empresas montadoras de motocicletas. Contudo observa-se que pela visão dos proprietários, pode-se propor que o sentimento de pertencimento e exclusividade é o que os mantêm ligados à marca, e em consequência ao HOG.

De acordo com Azevedo e Araújo (2010), a companhia soube administrar com destreza os problemas que surgiram e mantiveram a imagem da Harley Davidson flexível as mudanças de seus clientes, vinculando sua marca na mídia e nos filmes hollywoodianos, o que ajudou a formar um estereótipo do harleyro.

A Harley é específica na forma que os motociclistas sentam sobre ela, o 'ronco' de seus motores, o rock and roll como trilha sonora pelas highways nas longas viagens, até a figura de pessoas, em sua maioria homens, vestidas com jaquetas de couro preta, tatuagens de motoclubes, entre outros signos característicos da tribo dos motociclistas, em especial dos Harleyros. (AZEVEDO; ARAÚJO, 2010, p. 5).

Esse ainda é o imaginário que se tem dos grupos de motociclistas em geral, contudo é relevante mencionar que o rótulo de alcoólatras barbudos, e mal vestidos ficou no passado (AZEVEDO; ARAÚJO, 2010). Os autores afirmam que para além do estereótipo, os proprietários de uma Harley, buscam: status, sentimento de realização e uma válvula de escape para o estresse, dessa forma subentendem que apesar de poder escolher dentre outras marcas, o harleyro opta pela compra de uma Harley Davidson, não apenas pela qualidade reconhecida da marca, ou o ronco inconfundível do motor, mas ele o faz principalmente pela sensação de pertencimento e exclusividade que a motocicleta o proporciona.

A relação do harleyro com o estilo de vida Harley Davidson é quase uma religião. (SCHARF, 2011). Este autor afirma que é a identificação com o estilo de vida que confere o significado e importância dessa marca, e que a sensação de pertencer a um grupo exclusivo é o que faz homens e mulheres se deslocarem de outros países para participarem de eventos ou mesmo tatuarem a logomarca da Harley em seus corpos. Borges e Godinho (2008, p. 11) destacam ainda que para o harleyro a sua motocicleta "é um vínculo emocional com uma vasta comunidade".

\footnotetext{
${ }^{5}$ INTERBRAND: Empresa responsável pelas pesquisas que apontam as marcas mais valiosas do mundo. (REVISTA QUATRO RODAS, 2013).
} 
Foi a partir desse sentimento de pertencimento e exclusividade, que a filosofia do HOG está disseminada em 130 países e possui mais de um milhão de membros associados em mil e quatrocentos Chapters, sendo a maior organização de motociclistas no mundo. (IESA HARLEY DAVIDSON, 2013).

A partir do exposto neste tópico, é possível concluir que através do HOG, a Harley Davidson conseguiu manter um nível de relacionamento mais estreito com seus clientes, o que também levou a Companhia a ser reconhecida como uma das principais montadoras de motocicletas do mundo.

\section{RESULTADOS}

Os resultados aqui apresentados foram embasados pela pesquisa bibliográfica realizada referente ao segmento do mototurismo, os eventos motociclísticos e as agências especializadas nesse nicho, além do conhecimento obtido em sites, artigos e documentários sobre a história da Harley Davidson.

Através das entrevistas realizadas com membros da diretoria do HOG, e dos questionários respondidos pelos associados do grupo, bem como a pesquisa bibliográfica realizada, foi possível levantar informações sobre o Chapter HOG - The One Curitiba (PR), com o intuito de identificar as atividades ligadas ao turismo que realizavam.

Analisando essas informações pôde-se observar que, o valor emocional criado pela empresa Harley Davidson, considerando toda sua história familiar e suas peculiaridades, é o que faz com que ela dissemine um estilo de vida exclusivo. Estilo de vida esse que os membros do HOG se orgulham em ter, pois para a maior parte deles fazer parte dessa comunidade é pertencer a uma grande família, espalhada em 130 países e mais de mil e quatrocentos Chapters.

Conforme observado em pesquisa de campo e entrevistas realizadas para esta pesquisa, o Chapter HOG - The One Curitiba (PR) está ligado à concessionária Harley Davidson - The One, que é um empreendimento do Grupo Servopa. Foi inaugurada em 15 de dezembro de 2011, e possui mecânica para manutenção das motocicletas, lojas de venda de acessórios e souvenirs e espaço de convivência onde é realizado o tradicional 
café da manhã de sábado, sendo além de vendedora da motocicleta Harley Davidson um espaço de convívio dos associados do HOG.

Na pesquisa de campo, informações obtidas através das entrevistas e da análise de conteúdo nas redes sociais, foi possível constatar que o Chapter HOG The One, é uma organização que possui aproximadamente dois mil membros, contudo nem todos participam efetivamente das atividades desenvolvidas pelo grupo, verificando-se que na rede social do Chapter havia mil e setenta e oito pessoas. Essa organização possui um organograma composto por presidente, vice-presidente, tesoureiro e os Road's Captains, que são membros escolhidos pelo presidente para compor a diretoria, bem como duas representantes das Ladies of Harley (LOH), divisão dentro do HOG composto apenas por mulheres.

A análise dos dados obtidos através dos questionários aplicados aos membros do grupo apontou ser o Chapter HOG - The One Curitiba (PR) um grupo predominantemente composto por homens casados, com filhos, com idade superior a 35 anos, possuindo renda superior a dezesseis salários mínimos, instrução superior, residindo em Curitiba (PR), e apesar de possuir grande diversidade nas respostas, a maioria dos associados possuindo profissões de prestígio. Isso sugere que grande parte dos associados do Chapter HOG - The One Curitiba (PR) estava possuindo uma vida econômica e social estável, afirmando assim ser o HOG um grupo exclusivista, e as atividades turísticas que estava desenvolvendo caracterizando-se como turismo elitista.

Pôde-se observar ainda, ser o desejo de viajar um motivo influenciador no momento da compra de uma Harley Davidson, sendo possível ainda perceber que a sensação de liberdade estava sendo predominante durante as viagens realizadas pelo grupo estudado. Destaca-se que, grande parte dos membros realizava viagens de motocicleta frequentemente, fosse pelo simples prazer de sair da rotina, fosse para participarem de eventos.

Como já mencionado, os membros HOG demonstraram possuir o sentimento de pertencer a uma família, porém o que os mantinha unidos não eram os laços sanguíneos e sim a afinidade em comum por possuírem uma motocicleta, dessa forma assim como as famílias realizavam viagens e reuniões eles também o faziam. De modo geral a estrada era o principal destino desse grupo, contudo, as viagens realizadas pelo HOG se dividiam em dois tipos: bate-volta e bate-fica. 
As viagens de bate-volta acontecendo quinzenalmente em um raio de $200 \mathrm{~km}$ de Curitiba (PR), e tendo como principal intuito treinar os pilotos iniciantes. Já as viagens bate-fica aconteciam com menor frequência, devido a logística necessária para sua execução, normalmente a cada três meses.

A partir das informações obtidas com as entrevistas, afirma-se que o HOG organizava suas viagens tão bem quanto as agências profissionais que trabalhavam nesse segmento. $\mathrm{O}$ fato de possuir um calendário estipulando as datas que as próximas viagens de bate-fica seriam realizadas facilitava a organização e planejamento destes deslocamentos por parte da diretoria, sendo que as providências para a realização das viagens se iniciavam com no mínimo um mês de antecedência.

A pesquisa indicou que para a organização das viagens de bate-fica, as atribuições necessárias estavam sendo divididas entre os membros da diretoria, em reunião fechada. Entre as principais providências destacava-se: reserva de hotel e restaurante, solicitação de escolta policial e busca por patrocinadores, dessa forma sendo possível estipular o valor total da viagem.

Para informar os participantes sobre a execução da viagem, era elaborado um briefing, apresentado normalmente pelo presidente em um jantar alguns dias antes da viagem. Essas instruções também eram publicadas na página social do grupo, e se faziam necessárias principalmente para garantir a segurança dos motociclistas.

O briefing continha informações referentes aos horários de saída e chegada, distância e a rota que seria percorrida, as paradas que fariam no trajeto, a previsão do clima previsto para o dia da viagem, e os Road's Captains que seriam responsáveis pelo grupo.

Assim como as viagens de bate-fica, os eventos que o grupo promovia também eram estipulados no início do ano, e predefinidos no calendário, sendo que o principal patrocinador do grupo estava sendo a Concessionária The One.

Durante a pesquisa foi possível identificar que o Chapter HOG - The One Curitiba (PR) promovia dois tipos de eventos: de confraternização, organizados pelo HOG e filantrópicos, desenvolvidos principalmente pelas $\mathrm{LOH}$.

Os eventos de confraternização tendo o intuito principal de socializar os membros, e acontecendo principalmente aos sábados com o tradicional café da manhã, realizado na Concessionária The One, ponto de encontro dos HOG's. Além disso, o 
grupo também promovia eventos de maior porte em datas comemorativas, como natal, dia das mães e dos pais, ou em ocasiões especiais pré-programadas. Também realizavam eventos de cunho filantrópicos tendo por objetivo, arrecadar fundos ou mantimentos para instituições e pessoas carentes.

Em alguns eventos eram realizados cursos ou competições de manobras ou treinamentos de estrada. Esses treinamentos além de ser outra forma de socializar o grupo também permitiam maior interação dos novos membros com os associados há mais tempo. É relevante mencionar ainda que além de promover seus próprios eventos, o HOG também participava de eventos esporádicos de outros grupos de motociclistas, tanto em Curitiba quanto em outras cidades.

Considerando as informações obtidas, e alcançados os objetivos específicos com o intuito de estudar a relação entre o Chapter HOG - The One Curitiba e a atividade turística, tornou-se possível fazer algumas afirmações que demonstram essa relação. $\mathrm{O}$ Chapter HOG - The One, é um grupo que pratica o turismo de modo elitista, e suas atividades são exclusivas. $\mathrm{O}$ grupo realiza viagens com frequência, e durante a pesquisa observou-se que a principal motivação para a realização dessas viagens era a sensação de liberdade, o prazer de sair da rotina, e o interesse em participar de eventos.

O prazer de viajar com sua motocicleta era uma afinidade em comum neste grupo, e o destino principal era a estrada. Sendo assim, percebeu-se que o destino não era relevante para este grupo, mas sim o caminho que fariam para chegar até ele. $\mathrm{O}$ grupo realizava dois tipos de viagens, sendo que um tipo incluía pernoite, e outro não. Ambos os tipos de viagens sendo realizados periodicamente, e constavam em calendário pré-determinado pela diretoria do grupo, que era também a responsável pelo planejamento e organização desses deslocamentos.

Percebeu-se, portanto, que o grupo HOG - The One tinha uma estreita relação com a atividade turística, por realizarem viagens com frequência e periodicidade, e faziam uso da estrutura turística (hospedagem e alimentação, por exemplo) durante seus deslocamentos, o que movimentava o trade, mesmo que a motivação para esses deslocamentos não estivesse relacionada ao desejo de conhecer determinado destino ou atrativo, mas especialmente pelo prazer proporcionado pela ação de viajar. 


\section{CONSIDERAÇÕES FINAIS}

É necessário se considerar que o trabalho aqui exposto tratou sobre um grupo dentre os inúmeros espalhados pelo mundo. Esse grupo se mostrou ser organizado no que diz respeito à realização de suas viagens e eventos, contudo, considera-se ser precipitado afirmar que todo mototurista possui as mesmas condições e preferências do HOG.

Vale ainda a ressalva de que esse tipo de viagens também é realizado por motociclistas de forma autônoma. Diferente dos HOG's, pode acontecer de alguns motociclistas pegarem a estrada sem rota nem planos, com poucas condições financeiras se dispondo a se hospedarem em hotéis com menos conforto, ou até mesmo acampar, e nem sempre possuindo uma Harley Davidson, nem por isso deixando de ser mototuristas.

Dessa forma, percebeu-se que mesmo sendo considerado um segmento de minorias as vantagens do mototurismo se destacaram por vários fatores, tais como: não ter necessidade de um terminal, dando assim maior autonomia à viagem; ser um segmento que pode ser praticado por grupos, casais ou individualmente; os roteiros podendo ser comercializados através de agências viagens no formato de pacotes ou desenvolvidos pelos grupos de motociclistas, mas também podendo ser realizados através de itinerários independentes.

Assim o mototurismo pode ser considerado um segmento flexível, sem perder seu caráter de liberdade e aventura, onde independentemente da motocicleta, da distância, dos serviços que utilizam, ou mesmo a quantidade de pessoas que movimenta e, de maneira geral, os motociclistas viajam principalmente para interação com eles mesmos e com o meio a sua volta.

Vale destacar ainda, que os membros desse grupo demonstraram possuir bom poder aquisitivo, o que lhes proporcionava maior disponibilidade de recursos para realização das viagens e garantindo assim conforto e segurança durante as viagens e os eventos eram bem organizados e atendiam às expectativas e objetivos de seus membros.

Conforme detalhado no tópico anterior, considera-se que os objetivos propostos neste trabalho foram atingidos, a saber: levantamento de informações sobre o grupo de motociclistas do Chapter HOG - The One Curitiba (PR); identificação dos principais 
destinos de viagens desse grupo de motociclistas; análise da organização para as viagens; e identificação dos eventos organizados pelo Chapter HOG - The One Curitiba (PR). A partir disso, foi possível afirmar que os motociclistas do Chapter HOG (Harley Owners Grup) - The One Curitiba (PR) se relacionavam com a atividade turística com frequência, por realizarem eventos e viagens, movimentando assim o trade turístico.

A partir dessas informações, tornou-se possível identificar ainda que a relação do HOG com a atividade turística estava indo além do uso da infraestrutura turística durante suas viagens. De maneira geral os HOG's realizavam viagens e eventos principalmente para a interação do grupo, contudo o prazer e a liberdade sentida durante o trajeto tornavam-se mais importantes que o destino em si, funcionando assim como uma válvula de escape para aliviar as tensões cotidianas.

Por fim, considera-se que a temática do mototurismo ainda pode ser explorada de forma mais aprofundada, inclusive de modo a identificar outras questões ligadas a esse segmento, e como colaborar para melhorar os serviços a ele inerentes.

\section{REFERÊNCIAS}

ABRACICLO. Anuário ABRACICLO, 2012. Disponível em: <http://www.virapagina.com.br/abraciclo2012/>. Acesso em: 13/04/15.

AZEVEDO, B. M. M.; ARAUJO, M. M. C. A Marca Harley-Davidson no Brasil: o "Sonho" e os Entraves à Reprodução de uma Estratégia de Sucesso. V ENCONTRO NACIONAL DE ESTUDOS DO CONSUMO - ENEC, Setembro de 2010. Disponível em: <http://estudosdoconsumo.com.br/wp-content/uploads/2010/09/2.6_-_Bon..1.pdf>. Acesso em: 03/10/2013.

BENI, M. C. Análise Estrutural do Turismo. São Paulo: Senac, 2003.

BORGES, V. F.; GODINHO, L. C. Estratégia de Fidelização da Marca Harley Davidson na Perspectiva do Cliente. Belo Horizonte 2008. (mimeo.).

BRAGA, D. C. Agências de Viagens e Turismo: prática de mercado. Rio de Janeiro (RJ): Elsevier, 2008.

BURNS, P. M. Turismo e Antropologia. São Paulo, SP: Chronos, 2002.

COOPER, C.; FLETCHER, J.; WANHILL, S.; GILBERT, D.; SHEPHERD, R. Turismo: princípios e prática. Porto Alegre: Bookman, 2001. 
HARLEY DAVIDSON, 72 ${ }^{\text {a }}$ Daytona Bike Week. Disponível em: <http://www.harleydavidson.com/content/h-d/en_US/home/events/daytona.html>. Acesso em: 07/08/2013.

HOG CURITIBA CHAPTER THE ONE OFICIAL. Disponível em:

<https://www.facebook.com/groups/238399322934133/?fref=ts>. Acesso desde março de 2013.

IESA HARLEY DAVIDSON. Hog Conheça. Disponível em:

<http://www.grupoiesa.com.br/harley-institucional.php?i=13>. Acesso em: 07/04/2013.

IESEN, R. E.; BECKER, E. L. S. Encontro Mercocycle e sua Contribuição ao Turismo de Santa Maria - RS. Disponível em:

$<$ http://sites.unifra.br/Portals/36/CHUMANAS/2003/encontro.pdf $>$. Acesso em: 20/07/2013.

MOTO ON LINE. Motoclubes - conheça um pouco da história dos motoclubes. Disponível em: <http://www.motonline.com.br/motoclubes-conheca-um-pouco-dahistoria-dos-motoclubes/>. Acesso em: 16/04/2013.

MUNDO DAS MARCAS. Harley Davidson. 2006. Disponível em: $<$ http://mundodasmarcas.blogspot.com.br/2006/05/harley-davidson-rebeldia-sobreduas.html>. Acesso em: 12/04/2013.

PALHARES, G. L. Transportes Turísticos. São Paulo: Aleph, 2002.

PEREIRA, C. A. M. O que é contracultura. São Paulo: Editora Brasiliense. 1983. Disponível em: <http://pt.scribd.com/doc/91392986/eBook-Carlos-Alberto-MessederPereira-o-Que-e-Contracultura>. Acesso em: 25/08/2013.

PETROCCHI, M. Marketing para Destinos Turísticos: planejamento e gestão. São Paulo: Futura, 2004.

PROVETTI, R. História do Moto Clubismo. Disponível em:

<http://www.viagemdemoto.com/index.php/historia/155-a-historia-do-moto-clubismo>. Acesso em: 10/04/2013a.

História da Moto. Disponível em:

<http://www.viagemdemoto.com/index.php/historia/883-historia-da-moto>. Acesso em: 10/04/2013b.

$<$ http://viagemdemoto.com/index.php/noticias/harley-davidson/217-viagem-de-motoharley-davidson-hog>. Acesso em: 26/07/2013c.

Viagem de Moto pela Europa em 1953. Disponível em:

<http://www.viagemdemoto.com/index.php/historia/1131-viagem-de-moto-pela-europaem-1953>. Acesso em: 18/08/2013d. 
REVISTA QUATRO RODAS. Harley-Davidson cresce no Brasil. Disponível em: $<$ http://quatrorodas.abril.com.br/moto/reportagens/salto-alto-702193.shtml>. Acesso em: 02/08/2013.

SCHARF, E. R. O Estilo de Vida e a Experiência: Aspectos da Marca no Entendimento dos Seus Usuários. São Paulo: Revista Brasileira de Gestão de Negócios. 2011, v. 13, n. 38, p. 99-113, jan./mar. 2011.

SIQUEIRA, L. F. Considerações Importantes sobre o Turismo na Atualidade. Revista Turismo. 2004. Disponível em:

<http://www.revistaturismo.com.br/artigos/atualidade.html>. Acesso em: 10/04/2013.

TURISMO DE MOTO. A História do Mototurismo. Disponível em: $<$ http://www.turismo-de-moto.com/a-historia-do-mototurismo/>. Acesso em: 10/04/2013.

Recebido em: 28-08-2014.

Aprovado em: 27-09-2014. 